\title{
Smoking Behavior among Turkish Twins
}

\author{
Fazil ALIEV and Sevgi YURT ÖNCEL
}

\begin{abstract}
In this study we introduce the first adult twin study in Turkey, focused on smoking behavior, and laying the foundation to register all twins born in Turkey for research purposes. Using Turkish twins will contribute to our understanding of health problems in the context of cultural differences.
\end{abstract}

Index Terms-Smoking, Nicotine Dependence, Twin Models, ,Structural Equation Modeling, FTND-(Fagerstrom Test of Nicotine Dependence), Clustered Logistic Regression

\section{INTRODUCTION}

We assessed 309 adult twin pairs (339 males and 279 females) between ages 15 and 45 living in the Kirıkale and Ankara regions of Turkey, and administered a health and lifestyle interview which included questions about smoking status and smoking history. We analyzed the data using descriptive statistics, t-tests, chi-square tests, and bivariate and multivariate clustered logistic regression. In addition, we fit bivariate Structural Equation Models (SEM) to determine contributions of latent genetic and environmental factors to smoking outcomes in this sample.

\section{MATERIALS AND METHODS}

Design of the sample: The study was carried out at Kirıkkale University, in Kirıkkale, Turkey. Kirıkkale is a city in the central Anatolian region of Turkey. It is located $80 \mathrm{~km}$ east of Ankara, which is the capital of Turkey. We created a list of 1000 twin pairs using different sources: by asking schools, by using available municipality and health centers records and by inquiring in neighborhoods. A subset of 325 pairs (650 individuals) was selected randomly from those individuals over the age of 15 years. 626 individuals were interviewed with face-to-face interviews as a data collection method to ensure data quality. Four individuals refused the interview and we removed those pairs from the list. The final sample consisted of 618 individuals. The brief report about this study and sample characteristics are published by the authors in Oncel et al., 2013 [9].

Descriptive statistics, cross tables, and correlation analyses were performed with IBM SPSS-20. Assumptions about the Normal distribution of variables were tested using the Kolmogorov-Smirnov tests. We performed t-tests for equality of means of non-categorical variables (number of cigarettes per

This research is supported by Kırıkkale University Research Grant: KKU, 2009/43. F.A. is supported by TUBITAK grant 114C117.

F.A. is with the Department of African American Studies Virginia Commonwealth University, Richmond, VA, USA and Department of Actuarial and Risk Management, Karabuk University, Turkey

S.Y.O . is with the Department of Statistics, Faculty of Arts and Sciences, Kırıkkale University, Kırıkkale, 71100, TURKEY. day, and FTND score) between genders. In analyses including both twins we used family ID as a clustering variable. Risk factors for smoking were determined and assessed first by univariate clustered logistic regression, and then by multivariate clustered logistic regression involving significant predictors from the univariate logistic regression using SAS software Chi-square tests were used to determine whether there were significant associations between categorical variables. The Cramer's V for nominal by nominal variables and the Gamma for ordinal by nominal variables provided information about the strength of the association between two categorical variables. SEM was performed using the OpenMx software in $\mathrm{R}$ [6]. The classical twin study allows us to partition the variance in a trait into additive genetic (A), common environmental (C) and unique environmental (E) factors by comparing the similarity between monozygotic (MZ) and dizygotic (DZ) twins [5]. To partition the variance in liability to nicotine dependence (ND), it is necessary to take smoking initiation (SI) into account as ND is conditional on SI. This is modelled using the CCC model with a pathway connecting both phenotypes [2]. Estimates can be obtained for the A, C and E sources of variance in ND that are shared with SI, through the causal pathway, as well as for A, C and $\mathrm{E}$ factors contributing to ND, independent of SI. Analyses proceed with fitting a series of alternative models, testing the significance of the contributions of the different sources of variance using a maximum likelihood approach in which the best model is chosen using a combination of goodness-of-fit and parsimony.

\section{MAIN RESULtS}

178 participants (28.8\%) were identified as smokers, smoking every day for a month or longer, of which $79.2 \%$ were males and $20.8 \%$ were females. Means for number of cigarettes per day and FTND score were higher in males than in females, and age of onset was earlier in males. There was a significant positive correlation between FTND score and number of cigarettes smoked per day, and a significant negative correlation between both variables and age at onset of smoking. Our study showed that gender, presence of a smoking twin in the family, age, alcohol use, marital status, and daily sports activities, feeling moody all played a significant role in smoking behavior among twins. The twin analysis suggested that $79.5 \%$ of the liability to FTND was influenced by genetic factors and $20.5 \%$ by unique environment, while familial resemblance for smoking initiation was best explained by common environmental factors [10]. 


\section{CONCLUSIONS}

Marked differences in the prevalence of smoking behavior in men versus women are observed for the Turkish population. Genetic analyses showed that common environmental factors primarily contributed to smoking initiation while genetic factors explained a greater proportion of the variance in liability to nicotine dependence. Our study shows higher heritability estimate of FTND scores and higher shared environmental influence on smoking initiation for both males and females than reported in previous studies.

\section{ACKNOWLEDGMENT}

We are grateful to all twins participating in this study, their families and municipal officials for their help with data collection in this study. The authors also are grateful to anonymous referee for valuable comments and suggestions which helped to considerably improve the quality of the manuscript.

\section{REFERENCES}

[1] Fagerström, K. O., "Measuring degree of physical dependence to tobacco smoking with reference to individualization of treatment," Addictive behaviors, 3(3), 235-241, 1978. http://dx.doi.org/10.1016/0306-4603(78)90024-2

[2] Kendler, K. S., Neale, M. C., Sullivan, P., Corey, L. A., Gardner, C. O., \& Prescott, C. A., A population-based twin study in women of smoking initiation and nicotine dependence. Psychological medicine, 29(2), 299-308, 1999.

http://dx.doi.org/10.1017/S0033291798008022

[3] Maes, H. H., \& Neale, M. C., "Genetic modeling of tobacco use behavior and trajectories," NCI Tobacco Control Monograph Series, 20: Phenotypes and Endophenotypes: Foundations for Genetic Studies of Nicotine Use and Dependence (eds. Swan, G.E. et al.) publication no. 09-6366 (US National Institutes of Health, 2009), 2009.

[5] Neale, M. C., \& Maes, H. H., "Methodology for Genetic Studies of Twins and Families Kluwer Academic Publishers B.V.Dordrecht,” The Netherlands, 2002.

[6] Neale, M. C., Boker, S. M., Xie, G., \& Maes, H. H., "Mx: Statistical Modeling . Richmond, VA: Department of Psychiatry," Virginia Institute for Psychiatric and Behavior Genetics, Virginia Commonwealth University, 2003.

[7] Neale, B. M., Sullivan, P. F., \& Kendler, K. S. (2005). “A genome scan of neuroticism in nicotine dependent smokers," American Journal of Medical Genetics Part B: Neuropsychiatric Genetics, 132(1), 65-69. http://dx.doi.org/10.1002/ajmg.b.30095

[8] Öncel, S. Y., Gebizlioğlu, Ö. L., \& Alioğlu, F. A., "Risk factors for smoking behavior among university students," Turkish J Med Sci, 41, 1071-80, 2011.

[9] Öncel, S. Y., \& Aliev, F., "Turkish twin study: an initial step,” Twin Research \& Human Genetics, 16(1), 2013. http://dx.doi.org/10.1017/thg.2012.94

[10] Öncel, S. Y., Dick, D. M., Maes, H. H., \& Aliev,F. Risk factors influencing smoking behavior: a Turkish twin study. Twin Research and Human Genetics, 17(06), 563-573, 2014.

http://dx.doi.org/10.1017/thg.2014.43

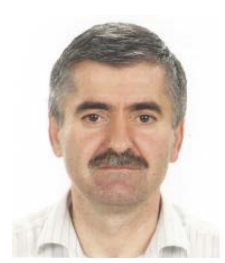

Fazil ALIEV was born in Muhah, Zagatala, Azerbaijan. He received the B.S. and M.S. , Ph.D degrees in statistics from Moscow State Unvdersity, Russia. He is a Professor of the Faculty of Business at Karabuk University, Turkey. His research interests include Statistics, Modeling and Applied Engineering.

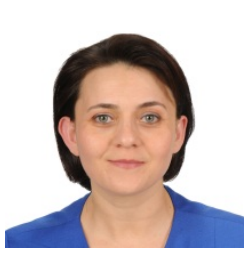

Sevgi YURT ONCEL was born in Ankara, Turkey.

She received the B.S. and M.S. , Ph.D degrees in statistics from the Ankara University, Turkey, in 1994 and 1997, 2002 respectively. She is a Professor of the Department of Statistics at Kırıkkale University/ Turkey. Her research interests include twin registry and statistics. 